\title{
Results from the NREL Variable-Speed Test Bed
}

Lee Jay Fingersh

Palmer W. Carlin

Presented at

ASME $17^{\text {th }}$ Wind Energy Symposium

Reno, Nevada

January 12-15, 1998

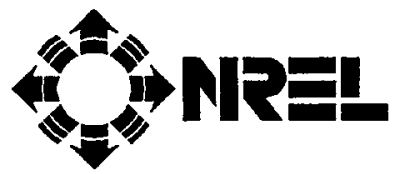

National Renewable Energy Laboratory 1617 Cole Boulevard Golden, Colorado 80401-3393

A national laboratory of the U.S. Department of Energy Managed by Midwest Research Institute for the U.S. Department of Energy under contract No. DE-AC36-83CH10093

Work performed under task number WE801330

November 1997 


\section{NOTICE}

This report was prepared as an account of work sponsored by an agency of the United States government. Neither the United States govemment nor any agency thereof, nor any of their employees, makes any warranty, express or implied, or assumes any legal liability or responsibility for the accuracy, completeness, or usefulness of any information, apparatus, product, or process disclosed, or represents that its use would not infringe privately owned rights. Reference herein to any specific commercial product, process, or service by trade name, trademark, manufacturer, or otherwise does not necessarily constitute or imply its endorsement, recommendation, or favoring by the United States govemment or any agency thereof. The views and opinions of authors expressed herein do not necessarily state or reflect those of the United States government or any agency thereof.

Available to DOE and DOE contractors from:

Office of Scientific and Technical Information (OSTI)

P.O. Box 62

Oak Ridge, TN 37831

Prices available by calling (423) 576-8401

Available to the public from:

National Technical Information Service (NTIS)

U.S. Department of Commerce

5285 Port Royal Road

Springfield, VA 22161

(703) $487-4650$ 


\title{
RESULTS FROM THE NREL VARIABLE-SPEED TEST BED
}

\author{
L. J. Fingersh, P. W. Carlin \\ National Renewable Energy Laboratory \\ National Wind Technology Center \\ Golden, Colorado
}

\begin{abstract}
$\underline{\text { Abstract }}$
The NREL Variable-Speed Test bed turbine has been used to examine the performance and controllability of a variable-speed, variable-pitch turbine. Control strategies that eliminate drive-train torque fluctuations in high winds have been published before and example data are given here. The energy capture of a variablespeed wind turbine depends in part on its ability to successfully operate at the peak of the $\mathrm{C}_{\mathrm{p}}-\lambda$ curve. The losses associated with the inability of the rotor to stay exactly on top of the curve at all have been found and quantified. New control strategies for improving energy capture in moderate winds are also proposed. The potential exists to improve overall energy capture by $5 \%$ or more.
\end{abstract}

\section{Introduction}

The NREL Variable Speed Testbed turbine is uniquely suited to examine both energy production and control strategies. It has a high-bandwidth $(>50 \mathrm{~Hz})$ PC-based controller that allows it to change control strategies while the turbine is online. Control can even be shifted from constant-speed to variable-speed operation. It also has an accurate way to measure rotor torque production which allows for a direct measurement of the mechanical energy captured from the wind regardless of the drive-train efficiency surface. Additionally, it has a servo-controlled electro-mechanical pitch control actuator for controlling the pitch of the three blades. Over the past year, many hours of data were taken using many different control methods.

Wind turbines generally have three regions of operation. Region 1 describes the start-up of the turbine. Region 2 is operation after start-up and before maximum power is reached. In this region, it is desired to maximize energy capture. When the power production of the rotor becomes more than the drivetrain can handle, a region of operation is entered during which the goal is to keep power limited to rated power while minimizing the stress on the turbine. This region is called region 3.
Nomenclature

$$
\begin{aligned}
& v=\text { current windspeed } \\
& r=\text { rotor radius } \\
& \rho=\text { air density } \\
& A=\text { rotor swept area } \\
& C_{p}=\text { rotor power coefficient } \\
& \lambda=\frac{\text { blade tip speed }}{\text { windspeed }} \quad(\text { tip }- \text { speed }- \text { ratio }) \\
& \omega=\text { rotor rotation rate }(\mathrm{rad} / \mathrm{s}) \\
& T=\text { rotor torque } \\
& J=\text { rotor inertia } \\
& C_{p 0}=\text { Peak value of } C_{p} \\
& \lambda_{0}=\lambda \text { at peak value of } C_{p} \\
& P=\text { Rotor Power }
\end{aligned}
$$

\section{Discussion}

\section{$\underline{\text { Region } 2}$}

From the simple relation:

$$
C_{p}=\frac{P}{\frac{1}{2} \rho A v^{3}}
$$

and the definitions:

$$
\begin{aligned}
& \lambda=\frac{\omega r}{v} \\
& P=T \omega
\end{aligned}
$$

it can easily be shown that the following relation holds for constant $\mathrm{C}_{\mathrm{p} 0}$ and constant $\lambda_{0}$. This will be called the variable-speed control law.

where

$$
T=k \omega^{2}
$$

$$
k=\frac{\rho \pi r^{5} C_{p 0}}{2 \lambda_{0}^{3}}
$$

This is the basic relation for operation of a variablespeed turbine. If $\mathrm{C}_{\mathrm{p} 0}$ and $\lambda_{0}$ are set to the values at the maximum of the $C_{p}-\lambda$ curve (see Figure 1), the turbine should, on average, operate at the peak of the $C_{p}-\lambda$ curve at all times. 


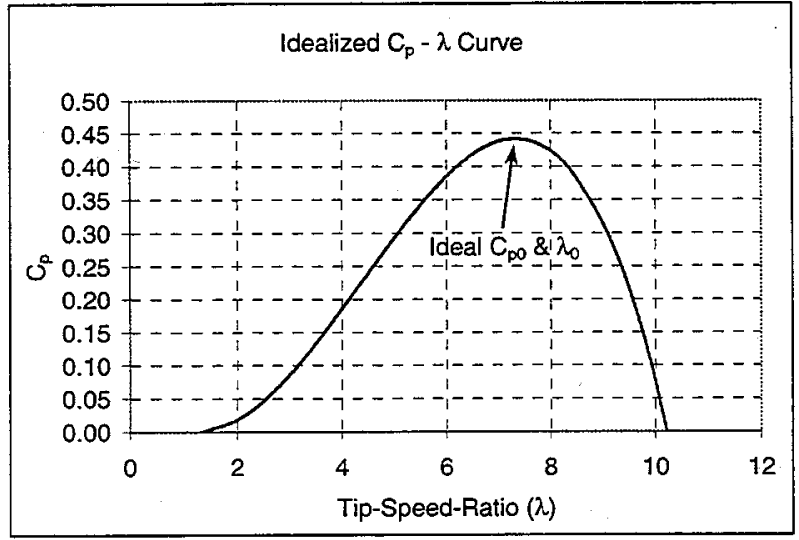

Figure 1 - An idealized $C_{p}-\lambda$ curve. If one sets the values of $C_{p 0}$ and $\lambda_{0}$ in the variable-speed control law to the values at the peak of the curve, the turbine should, on average, run optimally.

\section{Tracking Losses}

In order to determine the tracking losses associated with variable-speed operation, we have collected about 10 hours of $10 \mathrm{~Hz}$ variable-speed data. These data were used to generate instantaneous values of $\mathrm{C}_{\mathrm{p}}$, corrected for instantaneous air density. This $C_{p}$ data has been binned against wind. The result of this binning is shown in Figure 2. The idealized curve represents operation at the peak of the $\mathrm{C}_{\mathrm{p}}-\lambda$ curve in region 2 and perfect power limiting in region 3 .

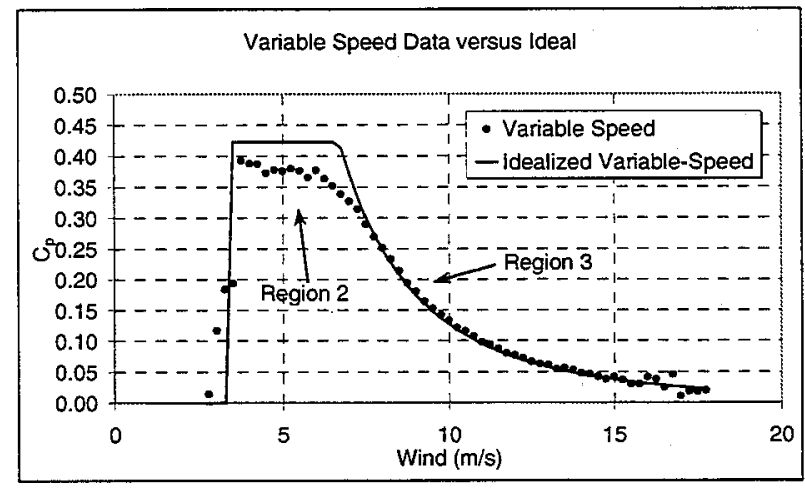

Figure 2 - Binned operation. Note the gap between variable-speed operation in region 2 and the idealized curve. The values of $\mathrm{C}_{\mathrm{p} 0}$ and $\lambda_{0}$ in the variable-speed control law were set at their values at the peak of the constant-speed $\mathrm{C}_{p^{-}}$ $\lambda$ curve.

One important thing to note about Figure 2 is the difference between the variable-speed curve and the idealized curve in Region 2. This gap is about $10 \%$ and is caused primarily by the inability of the rotor to accelerate and decelerate quickly enough to keep instantaneous $\lambda$ perfectly constant at the desired value $\lambda_{0}$. It is important to note that there is substantial error margin on this number (perhaps as much as 5\%) because of the limited data used in the analysis. Normally, hundreds of hours of data would be used. Here only about 10 hours were used. In the future, we intend to run more lengthy tests.

Another important thing to note is the accuracy to which the variable-speed curve follows the desired curve in region 3. The reason for this is that the control algorithm keeps the torque and speed (and hence power) essentially constant in region 3 regardless of the wind. Such behavior would yield a nearly perfectly flat power curve in region 3.

A gap of $10 \%$ in the average efficiency of a variablespeed turbine in region 2 is significant. It can lead to more than a 5\% loss in average annual energy production compared with idealized variable-speed operation. Since this ideal operation is often used to compare variable-speed operation with constant-speed operation, quantifying the difference is important.

The basic cause of the tracking losses is the sluggishness of the high-inertia rotor in tracking the wind. Fortunately, there are two controllable turbine functions that can be used to improve the rotor's ability to maintain a constant $\lambda$. Those functions are generator torque and blade pitch.

Generator torque can, in theory, be used to assist the rotor's acceleration and deceleration in response to changing winds. For example, if a wind gust comes along, one could reduce generator torque to allow the rotor to speed up at a higher rate. The problem is knowing when to take action and how much action to take.

One way to detect off-optimal performance is to detect rotor acceleration. If the rotor is already running at the desired optimum point, it will not accelerate or decelerate. However, if the wind were to increase, aerodynamic torque produced by the rotor would also increase and the rotor would begin to accelerate. This acceleration is the basis of how the variable-speed control law tracks the wind.

Having the ability to detect rotor acceleration gives us the ability to detect when the turbine is operating off of the optimal operating point. Figure 3 is an idealized representation of the net torque produced by a hypothetical rotor with optimal $C_{p}$ at a $\lambda$ of 7 . Net torque is the aerodynamic torque minus the torque 
absorbed by the generator when operating with the variable-speed control law. Notice that net-torque is a nearly linear function of $\lambda$ near the operating point. Since rotor acceleration can be measured and net torque is proportional to rotor acceleration, a measure of instantaneous $\lambda$ can theoretically be determined.

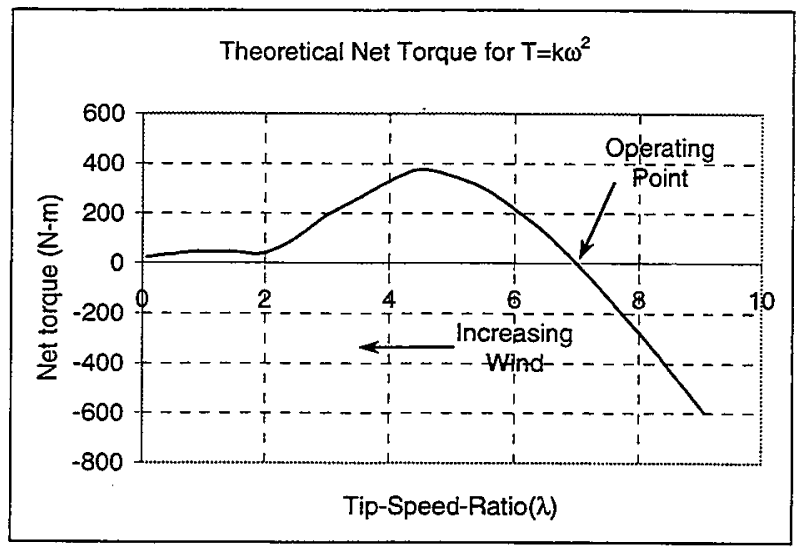

Figure 3 - Idealized (from the Prop code) net torque for a wind turbine operating under the variable-speed control law. Near the operating point, net torque is a nearly linear function of $\lambda$. Detecting rotor acceleration (and therefore net torque) can therefore provide an indication of current instantaneous $\lambda$.

Given the above discussion, a new control strategy can be proposed. This control strategy is a modification of the variable-speed control law. The law is modified through the addition of a second term.

where

$$
T=k \omega^{2}-G\left(T_{\text {aero }}-k \omega^{2}\right)
$$

$$
T_{\text {uero }}=T_{\text {shuft }}+J \dot{\omega}
$$

The new term in the control law uses a gain $G$ multiplied by the net torque of Figure 3 . This value is subtracted from the original control law. When the net torque is positive (at low values of $\lambda$ ), the term will be negative and the torque will be reduced. Conversely, when the net torque is negative, the torque will be increased. Both situations would lead the rotor to more rapidly approach the desired operating point.

Unfortunately, at this time, very little data have been collected from the turbine while operating under this new control law. Initial test runs and simulations indicate that the control law is stable and performs as desired. Preliminary data indicate the energy improvement is between $0.3 \%$ and $3 \%$. A great deal more testing is required in order to obtain a true measure of performance.

In some instances, instantaneous $\lambda$ can get very low. For example, a lull in the wind followed by a sudden gust can reduce instantaneous $\lambda$ to 3 or below. In such instances, the rotor can go deep into stall and therefore accelerate very slowly. To prevent the turbine from getting trapped at a low $\lambda$ for an extended length of time, blade pitch angle can be employed.

During such an event, pitching the blades to feather can drastically improve rotor acceleration. Figure 4 is an idealized schedule of pitch angles that yield optimal $C_{p}$ for a given $\lambda$. If $\lambda$ gets below about 5 in this case, pitching toward feather would increase turbine acceleration toward the optimal operating point. Unfortunately, in this case, measuring rotor acceleration is not sufficient to determine $\lambda$ below about 4.5. The reason for this is that the function in Figure 3 is not single-valued if values of $\lambda$ below 4.5 are included. For example, if the measured acceleration indicates a net torque of $200 \mathrm{~N}-\mathrm{m}, \lambda$ could be either 3 or 6 . Hence, in order to determine on which side of the peak in net torque we are operating, we must measure windspeed.

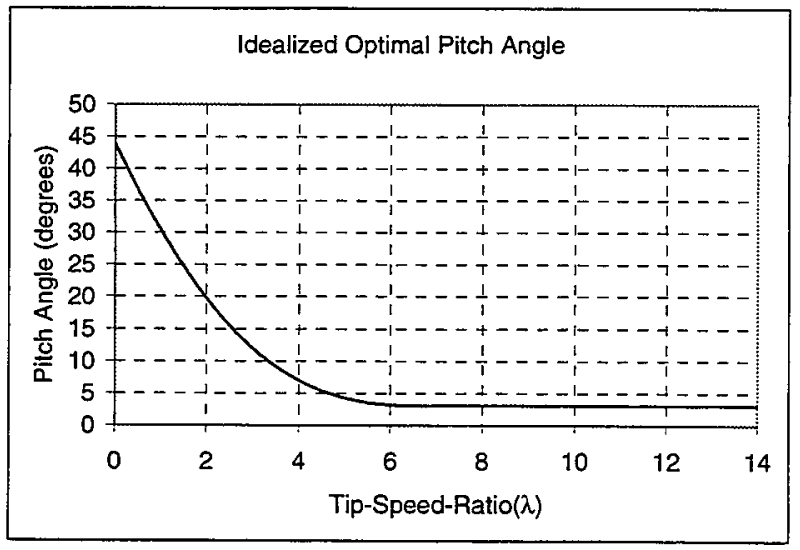

Figure 4 - Optimal pitch angle for a given $\lambda$. At $\lambda$ 's less than about 5 , it becomes desirable to begin to pitch toward feather.

\section{Systematic Losses}

All of the above arguments assume that the values of $C_{p}$ and $\lambda$ at the peak of the $C_{p}-\lambda$ curve are known. However, in practice, it is extremely difficult to know these values. The values may even change from day to day because of blade erosion or bug build-up. If one turbine is pitched slightly differently or if its blades came from a different mold, it may have values that are different from those of another turbine of the same type. 
These effects can cause the machine to run off the optimal point.

To quantify these "systematic" losses, the $C_{p}-\lambda$ curve of Figure 1 was used. The operating point was found over a range of $C_{p 0}$ and $\lambda_{0}$ values near the ideal values. The resulting region 2 energy production is displayed in Figures 5 and 6.

The effect of $C_{p 0}$ and $\lambda_{0}$ mismatch on energy capture

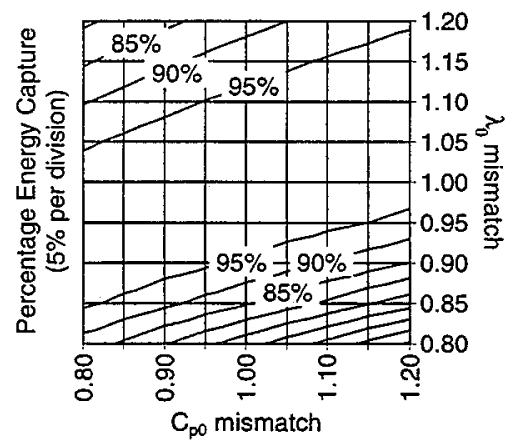

Figure 5 - Topographical map of losses due to incorrect tuning of $C_{p 0}$ and $\lambda_{0}$ values in the variable-speed control law.

The effect of $C_{p 0}$ and $\lambda_{0}$ mismatch on energy capture

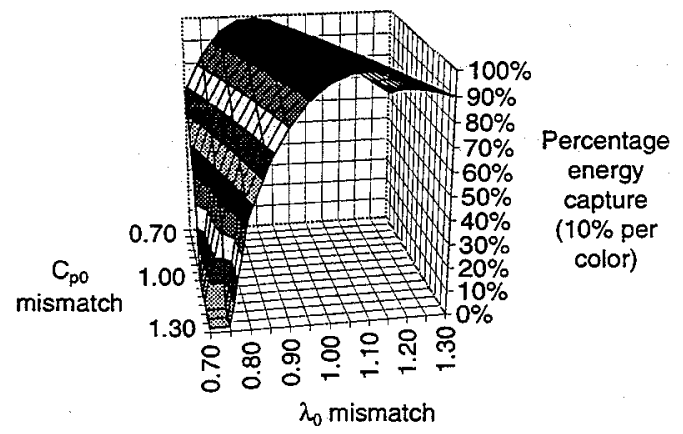

Figure 6 - 3-D view of the losses due to incorrect set points.

Note in the figures the stronger relationship between losses and $\lambda_{0}$ mismatch than those for $\mathrm{C}_{\mathrm{p} 0}$ mismatch. The reason for this is the fact that $\lambda_{0}$ is cubed in the control law and $\mathrm{C}_{\mathrm{p} 0}$ is raised only to the first power. In fact, $C_{p 0}$ mismatch in the figures could be replaced by $\rho$ since it is also raised only to the first power in the variable-speed control law. In other words, errors in $\rho$ are just as important as errors in the $\mathrm{C}_{\mathrm{p} 0}$ set point. Hence it may be important to measure local air density and use it in the control of the turbine to avoid losses associated with off-optimal operation. For example, a $\pm 10 \%$ error in air density can lead to roughly a $1 \%$ loss.

Another source of "systematic error" can be the drive system itself. If, for any reason, the drive system does not produce the commanded torque, off-optimal operation occurs. For example, if the power electronics system is not correctly tuned or if the gearbox efficiency is not well compensated for, the true shaft torque can be different than the desired torque. A torque that is $10 \%$ in error is equivalent to a $10 \%$ error in air density or $\mathrm{C}_{\mathrm{p} 0}$.

All of these sources of "systematic error" are essentially independent and so can either pile up or cancel out. If the turbine designer is fortunate, they cancel out. If not, they could pile up and lead to substantial off optimal operation. The loss is most sensitive to the $\lambda_{0}$ parameter and, unfortunately, this is the most difficult parameter to measure accurately because of the relative flatness of the $C_{p}-\lambda$ curve near its peak. Combine a $5 \%$ error in $\lambda_{0}$ with $5 \%$ errors in $\mathrm{C}_{\mathrm{p} 0}, \rho$ and torque and losses of $5 \%$ to $10 \%$ can be incurred.

\section{Region 3}

In region 3 operation, the goal is not to produce maximum energy but rather to produce only rated power and control turbine loads. This discussion will center on drive-train loads and power control. On large machines, gearbox loads are of great importance to the overall design of the machine. Hence, eliminating the well-known torque spikes associated with constantspeed operation is extremely desirable. Although the subject of blade loads is also of vital importance to turbine design, that subject is left to other publications.

The region 3 strategy used on this turbine has been published before. $^{3}$ The basic strategy is to control, independently, shaft torque and rotor speed. Controlling generator electrical load controls shaft torque. This can be accomplished using power electronics. Separately, controlling blade pitch angle using PID or another control algorithm controls the rotor speed. Properly tuned, such an algorithm can control torque and speed to within a few percent of desired. Figure 7 is an example of control in this region. 


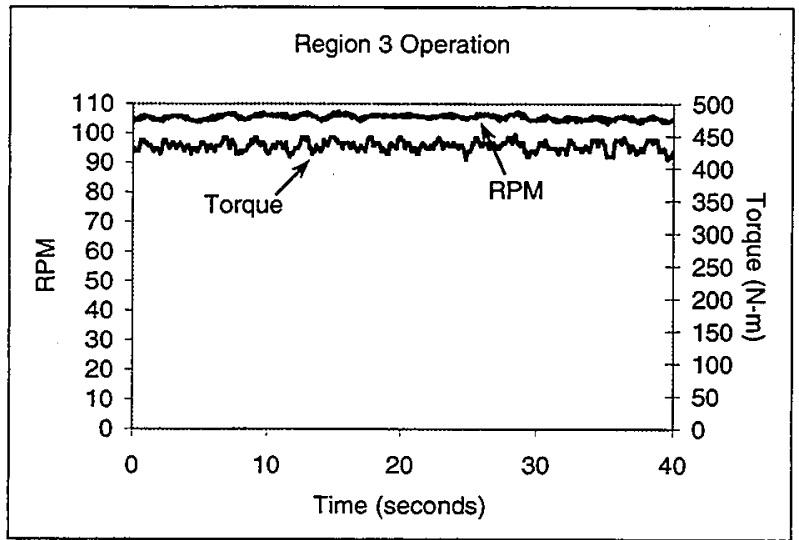

Figure 7 - Region 3 control. The control seeks to hold both torque and speed constant by controlling generator load and blade pitch angle. Using power electronics instead of the digital load bank used on this turbine would produce even better torque control.

\section{Conclusion}

In order to gain the full benefit of variable-speed operation, it is important to seek to minimize tracking losses caused by the stochastic wind environment. A strategy has been developed that could potentially reduce tracking losses. It is also important to correctly tune the variable speed algorithm in such a way that systematic losses are also avoided. Systematic losses can be caused by inaccuracies in the parameters in the variable-speed control law, namely $\mathrm{C}_{\mathrm{p} 0}, \lambda_{0}$ and $\rho$. It is quite difficult to know these parameters exactly but the resultant losses have been quantified.

Region 3 operation is important because high drivetrain loads are often associated with this region. A strategy has been developed and demonstrated that reduces the peak torque on the drive-train to a few percent above the turbine's nominal rated torque.

\section{Future Work}

In the future, we plan to run further tests on the turbine that will be designed to test other control strategies that are potentially important to reducing the cost of energy of a turbine of this nature. We intend to test control strategies that seek to further reduce tracking errors by controlling the pitch of the blades as well as the torque on the generator in region 2. We also intend to look at strategies to reduce fatigue loads on the turbine blades and tower.

\section{Acknowledgments}

The U. S. Department of Energy is credited for its funding of this document through the National Renewable Energy Laboratory under contract number DE-AC36-83CH10093.

\section{References}

${ }^{1}$ Carlin, P. "Some Analytic Expressions for Upper Limits on the Mean Annual Wind Turbine Power in a Rayleigh Wind Regime." Proceedings of the Wind Energy Symposium, January 1997, Reno, NV. Reston, VA: American Institute for Aeronautics and Astronautics.

2 Milborrow, D. "Are Variable Speed Production Benefits Being Oversold?" WindStats Newsletter; Spring 1996, Vol. 9, No. 2, pp 6-7.

${ }^{3}$ Carlin, P. Fingersh, L. "Some Preliminary Results from the NWTC Direct-Drive, Variable-Speed Test Bed." Proceedings of the Wind Energy Symposium, January 1997, Reno, NV. Reston, VA: American Institute for Aeronautics and Astronautics.

${ }^{4}$ Fingersh, L. Robinson, M. "The Effects of Variable Speed and Drive Train Component Efficiencies on Wind Turbine Energy Capture." Proceedings of the Wind Energy Symposium, January 1997, Reno, NV. Reston, VA: American Institute for Aeronautics and Astronautics. 